\title{
Cidades Médias na Amazônia Legal: Araguaína/TO, Imperatriz/MA e Marabá/PA - indutoras de desenvolvimento $e$ desigualdades
}

\author{
Miguel Pacífico Filho \\ Universidade Federal do Tocantins - Palmas - TO - Brasil \\ ORCID: http://orcid.org/0000-0002-0316-2326 \\ Thelma Pontes Borges \\ Universidade Federal do Tocantins - Palmas - TO - Brasil \\ ORCID: http://orcid.org/0000-0001-6073-8937 \\ Marcela Pereira Lima Teles \\ Universidade Federal do Tocantins - Palmas - TO - Brasil \\ ORCID: http://orcid.org/0000-0003-3369-3790 \\ Airton Cardoso Cançado \\ Universidade Federal do Tocantins - Palmas - TO - Brasil \\ ORCID: http://orcid.org/0000-0003-4698-1804
}

\section{Resumo}

As cidades de Araguaína/TO, Imperatriz/MA e Marabá/PA fazem parte da chamada Amazônia Legal, caracterizam-se como cidades médias e são classificadas como capitais regionais C pelo IBGE. Cada uma delas é referência em suas respectivas regiões geográficas intermediárias e limítrofes entre si. O objetivo do trabalho é demonstrar que as três localidades, apesar de apresentarem crescimento econômico e demográfico forte, padecem de problemas sociais e estruturais que diminuem a qualidade de vida de sua população. Para tanto, utilizou-se de dados secundários das fontes IBGE - Cidades, Atlas do Desenvolvimento Humano, Instituto Trata Brasil, IPEADATA e Comex Stat referentes a crescimento demográfico, exportações, IDH, PIB, homicídios, Cadastro Único, Programa Bolsa Família, acesso à água, à coleta e ao tratamento de esgoto. Como resultado percebemos que há crescimento demográfico, econômico e de exportações, bem como renda per capita acima da média nacional, qualificando as cidades médias estudadas como efeitos promissores das políticas de desenvolvimento para a Amazônia; contudo os dados de saneamento básico, homicídios e população no cadastro único demonstram que os aspectos econômicos não se reverteram em bem-estar-social. Concluiu-se que os dados induzem à compreensão de que mesmo com todo crescimento econômico, as liberdades instrumentais e substantivas ainda permanecem relegadas e que uma das possibilidades de 
superação está num olhar mais integrado das três cidades em termos geográficos e administrativos.

Palavras-chave: Amazônia Legal. Desenvolvimento. Araguaína. Imperatriz. Marabá.

\section{Medium Cities in the Legal Amazon: Araguaína/TO, Imperatriz/MA and Marabá/PA - inducers of development and inequalities}

\section{Abstract}

The cities of Araguaína / TO, Imperatriz / MA and Marabá / PA are part of the Legal Amazon, are characterized as medium-sized cities and are designated as regional capitals $C$ by IBGE. Each of them is a reference in their respective intermediate and bordering geographic regions. The objective of the work is to demonstrate which the three locations, despite presenting strong economic and demographic growth, suffer from social and structural problems that reduce the quality of life of their population. For this purpose, secondary data from IBGE sources - Cities, Atlas of Human Development, Instituto Brazil, IPEADATA and Comex Stat were used, referring to demographic growth, exports, HDI, GDP, homicides, Cadastro Único, Bolsa Família, access to water, sewage collection and treatment. As a result, it is perceived that there is a demographic growth for the Amazon; therefore sanitation, homicides, and population data on the single registry present that the economical aspects have not been converted into social welfare. Thus, it can be conclude that the data induce the understanding even considering that economic growth, instrumental and substantive freedoms are still relegated and that one of the possibilities for overcoming lies in a more integrated perspective of the three cities in geographical and administrative terms.

Keywords: Legal Amazon. Development. Araguaína. Imperatriz. Marabá

\section{Ciudades medias en el Amazonas legal: Araguaína en Tocantins Emperatriz en Marañao y Marabá en Pará como introductorias del desarrollo y desigualdades. \\ Resumen}

Las ciudades de Araguaína en Tocantins, Imperatriz en Maranhão y Marabá en Pará forman parte del Amazonas legal, se caracterizan como ciudades medias y son denominadas capitales regionales C por el IBGE (Instituto Brasileño de Geografía y Estadística). Cada una de ellas es referencia en sus respectivas regiones geográficas intermedias y limítrofes entre sí. El objetivo del trabajo es demostrar que las tres localidades, pese a que presentan crecimiento económico y demográfico fuerte, parecen problemas sociales y estructurales que disminuyen la calidad de vida en la población. Para este trabajo se utilizaron datos secundarios de las fuentes IBGE - ciudades atlas del desarrollo humano, instituto trata Brasil, IPEADATA y Comex stat, referentes al crecimiento demográfico, índices, IDH, PIB, homicidios, Registro único, programa "beca familia", acceso al agua, recolección y tratamiento del alcantarillado. Se adoptó la perspectiva Semana de desarrollo y se concluye que los datos inducen a la comprensión que todo el crecimiento económico las libertades instrumentales y las substantivas todavía permanecen relegadas, y que, y una de las posibilidades para superarla se encuentra en una visión más integrada de las tres ciudades en términos geográficos y administrativos.

Palabras clave: Legal Amazon. Desarrollo. Araguaína. Imperatriz. Marabá. 


\section{Introdução}

O contexto amazônico é marcado por significativas disparidades sócio ambientais, biomas condicionaram a ocupação em temporalidades distintas por povos e cidades de tipologias diversas e tais ocupações foram igualmente responsáveis por transformações impostas aos biomas. Porto (2015, 2020) menciona a complexa dinâmica socio geográfica observável na Amazônia, onde, ainda nos dias de hoje, aproximadamente 180 línguas são faladas; na qual organizase os espaços a partir de variáveis mais antigas como os rios e mais recentes como as estradas; onde a complexidade das dinâmicas internas contrasta com a visão externa homogeneizante que a reduz a floresta, reserva de recursos e fragilidade em indicadores sociais. Beltrão \& Lacerda (2017), mencionam a busca pela via interpretativa interdisciplinar acerca das identidades que se estruturam pelos agentes sociais em razão das rápidas mudanças pelas quais passam os contextos rurais e urbanos na amazônia da contemporaneidade.

Sendo assim, discutir essa pluralidade requer denominadores comuns. Tal perspectiva impõe necessidade de vigilância metodológica a fim de não deixar escapar particularidades, especificidades, sem as quais estaria limitada a compreensão de frentes distintas e complementares: a madeireira, a hidroelétrica, a agrícola, a empresarial, a migratória, a mineradora; todas elas compondo a questão urbana. Monte-Mór (2006) propõe a expressão urbanização extensiva para sintetizar como o binômio energia-transporte materializou-se a partir da segunda metade do século XX no Brasil em investimentos em rodovias, hidroelétrica, redes de comunicação e serviços. Numa associação entre capitais internacionais, elites nacionais e regionais estrategicamente alicerçadas por sucessivos ciclos de gestão político-nacional, "a urbanização extensiva caminha assim ao longo dos eixos viários e redes de comunicação e de serviços em regiões 'novas' como a Amazônia e o Centro-Oeste" (MONTE-MÓR, 2006, p. 12).

Considerando o contexto acima, propomos apresentar neste trabalho as cidades de Araguaína, no Tocantins, Imperatriz, no Maranhão, e Marabá, no Pará; classificadas como Capitais Regionais C no REGIC 2018 (IBGE, 2020), sob a perspectiva daquilo que Becker (1995) entende por floresta urbanizada, marcada por dinamicidade e heterogeneidade, pelo conflito e pela constituição do chamado trabalho novo. Tal discussão busca demonstrar, a partir do debate proposto por Sposito (2006) sobre redes urbanas e cidades médias, que tais configurações proporcionaram desenvolvimento econômico e crescimento demográfico, mas foram incapazes de dinamizar desenvolvimento de bases sociais de acordo com o que propõe Sen $(2010,2015)$ ao defender que as liberdades substantivas devem ser garantidas sob pena de haver uma fratura entre crescimento econômico/aumento da renda per capita e qualidade de vida. Pinheiro (2012) considera que é possível se apropriar do debate sobre ampliação das liberdades como instrumento estratégico de orientação e definição de políticas públicas para o desenvolvimento.

O fator econômico impulsionado em detrimento dos indicadores de desenvolvimento social é analisado a partir das discussões sobre desenvolvimentismo propostas por Johnson (1982, 1999), Perissinotto (2014) e Bishop e Payne (2018), bem como por Sen (2010) a fim de subsidiar o debate acerca do desenvolvimento a partir de um viés que considera as capacidades humanas. As 
três cidades formam um triangulo de vértices semi-equidistantes e compartilham áreas de influência; cabe dizer que a justificativa para delimitação se encontra nas interrelações econômico-sociais entre as três cidades supramencionadas que são apontadas por pesquisadores, com objetivos distintos daqueles aqui pretendidos. É o caso dos trabalhos de Gomes Júnior (2014) e Araújo (2016) nos quais mencionam, ao estudar separadamente cada uma das cidades, a possibilidade de interações sociais comuns a partir de sua proximidade geográfica. Becker (2013) ao discutir a dinâmica urbana na amazônia menciona o chamado policentrismo das cidades; e as três que delimitamos são também apontadas como representantes desse policentrismo na confluência dos estados do Tocantins, Pará e Maranhão. Tal policentrismo é também dinamizado por eixos viários como a Estrada de Ferro Carajás, a Ferrovia Norte-sul e a Rodovia Belém - Brasília.

Portanto, é a partir da dinâmica observada em cada uma das cidades que estruturamos este trabalho em 6 tópicos. No primeiro, demonstramos os propósitos do trabalho, sua problematização e sua estrutura. No segundo discutiremos as cidades médias e as dinâmicas urbanas na Amazônia Legal num primeiro instante, e, o debate acerca das liberdades substantivas num segundo momento. No terceiro é apresentada a definição metodológica do trabalho; e num quarto e quinto momentos serão abordadas as três cidades em seus aspectos formativos intrinsecamente vinculados ao desenvolvimentismo posto em prática no Brasil a partir da segunda metade do século XX. Serão demonstrados dados para sustentação da proposição deste trabalho: aspectos econômicos significativos e indicadores sociais frágeis; para isso, as bases de indicadores consultadas foram: IBGE - Cidades, Atlas do Desenvolvimento Humano, Trata Brasil, IPEADATA e Comex Stat. Nas considerações finais, debateremos como a falta de um plano integrado para as três localidades e a ausência de uma visão ampliada de desenvolvimento a partir das liberdades substantivas dificultam um alavancar da região e consequentemente barram o progresso socioeconômico que resultaria em melhoria da qualidade de vida de toda uma população.

\section{Dinâmicas urbanas na Amazônia Legal: cidades médias e Liberdades Substantivas}

O processo de urbanização no Brasil traz consigo tanto características legadas por um histórico de relação de dependência com Estados e metrópoles europeias quanto com os diversos planos de desenvolvimento postos em prática pelos poderes públicos em suas diversas instâncias. Tais características assumirão caráter de condicionante quando observamos as três cidades objeto desta pesquisa e suas atividades produtivas de referência, a saber: Araguaína voltada à prestação de serviços e ao agronegócio, sobretudo à pecuária de corte; Imperatriz à produção de celulose; e Marabá à mineração. Todas circunscritas ao mercado global de commodities. De acordo com Pinheiro (2007), quando se observa o espaço urbano no Brasil, constata-se que a condição colonial e consequentemente de economia periférica que ainda ecoa em muitas de nossas concepções e visões de mundo resulta em espaços diretamente vinculados às atividades exportadoras referenciadas em produtos cuja demanda é preexistente nas relações comerciais com pontos-referência no Hemisfério Norte.

A dinâmica apontada acima tem como um de seus muitos desdobramentos as chamadas cidades médias. Cabe reafirmar que durante as décadas de 1970 e 1980 
do século $\mathrm{XX}$ iniciativas federais propuseram perspectivas de suporte $\mathrm{e}$ desenvolvimento para tais configurações urbanas, pode-se mencionar o II Plano Nacional de Desenvolvimento do Brasil (II PND, 1975) cujo objetivo foi o de dinamizar as cidades de porte médio afim de reduzir as disparidades sociais e econômicas entre as regiões brasileiras (RAMOS, 2011, p. 37).

Entendidas como parte do recente processo de urbanização brasileiro, também portadoras de características herdadas de uma lógica político-comercial de dependência, as cidades médias revestem-se de papel de destaque tanto no estabelecimento de novas referências político-comerciais quanto como objeto de reflexões acadêmicas. Cabe dizer que, ainda dentro do recorte temporal mencionado acima, a década de 1970 , se observa a origem de uma área de conhecimento destinada a observar e problematizar o urbano e suas diversas possibilidades de recortes temáticos: “Os primeiros programas de pós-graduação em planejamento urbano e regional foram criados no início dos anos 70 em Recife, Brasília e Rio de Janeiro, São Paulo e Porto Alegre" (BRASIL, 2019, p. 4).

É possível afirmar que as três últimas décadas do século $\mathrm{XX}$ assistem no Brasil a um movimento de expansão urbana sustentado tanto pela ampliação de atividades intrínsecas a economias periféricas, como mineração, quanto por revoluções tecnológicas no campo que permitem, por exemplo, ampliar a fronteira agrícola na direção da região Centro-Norte. No que diz respeito a esta última região, é necessário mencionar os planos PRODECER, POLOAMAZONIA e POLOCENTRO bem como o acordo Brasil-Japão, ações que interferiram sobremaneira no perfil de ocupação e estruturação de cidades que se desenvolveram em estados como Mato Grosso, Mato Grosso do Sul e Goiás. Ressalte-se que em relação ao supracitado acordo a Japan International Cooperation Agency (JICA) menciona-se a intenção de transformar uma área que segundo sua leitura era inexplorada naquilo que seria o chamado "celeiro do mundo". O resultado prático de tal operação foi a materialização de empreendimentos sojicultores em larga escala e centros urbanos que gravitam em torno de tais atividades.

Considerando-se o contexto até aqui descrito, pode-se mencionar a expressão urbanização-extensiva, que, de acordo com Monte-Mór (2006), nos permite concluir que fronteiras urbanas são integradas à dinâmica urbanoindustrial. Observa-se a incorporação de regiões amazônicas e do centro norte brasileiros apoiada por novos e extensos eixos viários bem como por redes de prestação de serviços nas mais diversas áreas. Reiteramos a afirmação de que as cidades médias se apresentam como fator de considerável relevância partindo da compreensão de que durante as décadas de 1980 e 1990 a estrutura urbana brasileira se altera com as metrópoles perdendo o protagonismo de crescimento populacional em detrimento das cidades de médio porte (PINHEIRO, 2007, p. 67).

Sendo assim, entende-se que essa nova configuração observada na malha urbana do Brasil apresenta-se como desdobramento de significativos reajustes das relações de produção do capital que ressignificam regiões anteriormente consideradas secundárias no cenário produtivo nacional (RAMOS, 2011). Contudo, tal reordenamento não se converteu em melhorias expressivas na qualidade de vida de suas populações.

Para o ordenamento do trabalho, dedicamos a próxima parte à discussão acerca das cidades médias e na sequência apresentamos o debate acerca do 
desenvolvimento a partir do acesso as liberdades substantivas. Tal disposição permite subsidiar teoricamente a pujança e a vulnerabilidade presente no contexto das cidades estudadas.

\subsection{As cidades médias e o contexto Amazônico}

A discussão sobre as cidades médias parte também de uma definição do Instituto Brasileiro de Geografia e Estatística (IBGE), que atribui tal classificação àquelas que possuem entre 100 e 500 mil habitantes. No entanto, constata-se na literatura que se dedica ao tema um consenso acerca das ainda imprecisas definições conceituais sobre aquilo que se entende como cidades médias. Há considerações a respeito dos papéis de centralidade desempenhados nas regiões em que estão inseridas e consideram-se variáveis como: produção econômica, atratividade migratória e rede de prestação de serviços, observáveis em Sposito (2006), Monte-Mór (2006), Sodré e Ramires (2017) e Santos (2017). Optamos neste trabalho por uma definição de cidade média que se constrói a partir da proposição de dois outros trabalhos dos quais trataremos a seguir.

Publicados no mesmo ano, os trabalhos de Amorim Filho e Serra (2008) e o de Mota e Matta (2008) propõem que a cidade média pode ser uma estrutura capaz de equilibrar fatores de atratividade existentes tanto em grandes metrópoles quanto nas chamadas pequenas cidades, capazes de equilibrar crescimento econômico, rede de transportes capaz de estabelecer fluxo de deslocamento para metrópoles regionais e prestação de serviços em áreas distintas e complementares, como educação e saúde. Sendo assim, o primeiro desses trabalhos define as cidades médias como sendo aquelas capazes de atender às expectativas tanto de moradores metropolitanos quanto interioranos ao conciliar acesso à serviços e bens com a segurança e temporalidades mais lentas típicas do interior (AMORIM FILHO; SERRA, 2008).

Propõe-se o equilíbrio entre a possibilidade de ampliação de horizonte educacional e atividade econômica pulsante, bem como a capacidade de um mesmo corpo social comportar-se como um híbrido de metrópole e cidade pequena. Em suma a intenção primeira seria a de se evitar as chamadas deseconomias metropolitanas e seus altos custos de manutenção e deslocamentos (Mota; Matta, 2008)

Seria então o hibridismo, de acordo com determinadas possibilidades interpretativas, uma das características centrais das cidades médias. No entanto, observa-se nos desdobramentos recentes das discussões acerca de tais configurações urbanas propostas que abrigam aspectos compreendidos desde a reestruturação conceitual até a legitimação de novas variáveis delimitadoras.

Lima (2017, p. 3) propõe "uma alternativa denominal e conceitual para o agrupamento de cidades, qualificadas como médias [...] de fortes representações e expressividades, marcadamente regionais". Constrói-se a proposta de um novo referencial conceitual, a saber, cidades de comando regional. A partir de consideração da capacidade indutiva nas regiões nas quais estão inseridas e 
observadas funcionalidades em diversas esferas, quer da reprodução de capitais, quer da disponibilidade de atendimento ao consumo, tal definição tem como seu pilar central o abandono da referência de um determinado perfil demográfico. Seriam, portanto,

cidades, independente de seus tamanhos, mas dotadas de capacidades produtivas, com funcionalidades diversas e inseridas dentro dos diferentes circuitos de investimentos capitais, responsáveis para processos de integração e desenvolvimento regional (LIMA, 2017, p. 15).

Tanto o hibridismo quanto o caráter de protagonismo ou comando regional são características observáveis nas cidades objeto desta pesquisa. Utilizaremos essas duas balizas para problematizar numa perspectiva comparativa as três cidades: Araguaína, no Tocantins, Marabá, no Pará, e Imperatriz, no Maranhão. Localizadas em estados limítrofes da chamada Amazônia Legal, as três referências dividem o protagonismo em seus respectivos estados imediatamente após suas capitais: Belém, São Luís e Palmas; e serão lidas a partir da percepção formulada pela geógrafa Becker (1995), floresta urbanizada. Tal perspectiva interpretativa busca externar o dinamismo das diversas constituições de espaços urbanos encontrados na Amazônia, ou, na definição da própria autora em questão: a urbe amazônida (BECKER, 2013). De acordo com um de seus intérpretes, Trindade Júnior (2013, p. 98), o legado de Becker reside no sentido de demonstrar a diversidade urbana na Amazônia.

Acentua-se o caráter da diversidade e da questão urbana na Amazônia. As dinâmicas estruturadas pelas diferentes tipologias de cidades resultaram, nas últimas décadas, em trabalhos de pesquisa cuja preocupação primeira foi revelar questões intrínsecas a tal processo: Hurtienne (2001), Sousa (2013), Gomes Junior e Nascimento (2014) e Santos (2017). O denominador comum a essas pesquisas é a demonstração de especificidades urbanas intrarregionais na Amazônia bem como a existência de relações multifacetadas com a biodiversidade presente na região. Novamente Trindade Junior (2013), ao esquematizar o percurso de pesquisa de Becker, nos mostra como essa autora contribui significativamente para a estruturação dessa compreensão demonstrando também a diversidade entre as regiões que compõem a Amazônia com distintos níveis de diferenciação em seus processos de urbanização. Aponta-se como exemplo de elevada diversidade o conjunto de estados composto por Rondônia, Mato Grosso, Tocantins e Pará.

Consideramos que a heterogeneidade das cidades na Amazônia Legal, especificamente das cidades médias, com seu hibridismo que convoca, por um lado, uma cidade com ampla gama de serviços (típicas das metrópoles) e, por outro, a manutenção da qualidade de vida (típica das cidades pequenas), além de seus protagonismos nas regiões de influência, encontram-se em estado de extrema fragilidade e de possível ruptura quando fatores sociais são pouco considerados, elevando-se a tensão entre a visão de cidades pujantes e a de cidades com alto grau de discrepâncias sociais. Sob esta ótica faz-se necessário um debate acerca da incorporação do olhar de Amartya Sen (2010) sobre as liberdades substantivas como leitura social e como instrumento capaz de diagnosticar e subsidiar instituições e governos para promoção de um desenvolvimento que considere, além de fatores econômicos, aqueles que se referem à melhoria da qualidade de vida de uma população. 


\subsection{Liberdades Substantivas como desenvolvimento}

As ideias de Sen (2010) servem de base para a ampliação do conceito de desenvolvimento, que até meados do século XX era atrelado apenas a crescimento econômico. As premissas postas pelo autor levam em consideração a necessidade de fomentar as capacidades humanas como forma de disseminar um desenvolvimento mais equitativo em que as liberdades substantivas são alçadas. Pinheiro (2012, p. 10) nos diz que "por sua vez, a noção de capacidades [capabilities] não se dissocia da noção de oportunidades, o que nos permite afirmar que as capacidades humanas são liberdades de determinado tipo". Desenvolvimento refere-se então à ampliação das habilidades reais, de vários tipos, e seu advento é propulsor do processo.

Nessa lógica, quanto mais liberdades forem ampliadas pelos cidadãos, mais desenvolvimento um país terá, trazendo ao centro o ser humano como objetivo primeiro. Assim sendo, considera-se o conceito de desenvolvimento como liberdade de forma multidimensional, tendo-se na renda per capita uma de suas dimensionalidades; as demais estão calcadas no pressuposto de que qualquer indivíduo, para ter qualidade de vida, necessita ter condições adequadas para que suas capacidades adquiram aquilo que ele deseja ter. Nesse sentido, o conceito de desenvolvimento é inerente ao de aumento das capacidades individuais ou das liberdades substantivas.

A base da teoria seniana é a funcionalidade de um sistema que permite a todo indivíduo ampliar suas capacidades ao máximo garantindo uma equidade de forças nas conquistas do bem-estar social. Para que se tenha a possibilidade de expandir capacidades, as funcionalidades mais básicas precisam ser sanadas: o acesso à nutrição adequada e a assistência à promoção da saúde, à eliminação de doenças, à segurança, à habitação e ao saneamento básico encontram-se aí enquadrados. A partir dessas, outras podem se estabelecer, como a participação política e a possibilidade efetiva de escolhas nas vidas privada e coletiva. Em outros termos, o desenvolvimento das liberdades substantivas é a alteração do foco para desenvolver os meios de satisfazer os fins. O autor não desconsidera os aspectos individuais, como gênero, idade e fatores emocionais, por exemplo, nem os fatores sociais, como riqueza, acesso a bens culturais e linguísticos, entre outros. É o acesso às liberdades, unido às características individuais, que forjará as escolhas pessoais e sociais do sujeito (SEN, 2010).

Existe uma distinção teórica entre liberdades substantivas e liberdades instrumentais, sendo as primeiras aquelas que se referem à ampliação de nossas condições avaliativas e de ações e que possibilitam um enriquecimento pessoal e a instrumentalização para ascender aos objetivos da própria vida, ou seja, mobilizar os meios para alcançar os fins; e as segundas, as liberdades instrumentais, são meios para chegar aos fins (SEN, 2010). Nesse sentido, apresentaremos a seguir dados que atestam que uma parte da população das localidades estudadas não atinge nem ao menos as liberdades instrumentais, permitindo compreender que, como as liberdades substantivas são o cerne do conceito de desenvolvimento e que se permitem ser utilizadas como referencial avaliativo de tal processo, as cidades de Araguaína, Imperatriz e Marabá apresentam apenas dados de crescimento 
econômico, mas que não se revelam na mesma proporção quanto ao desenvolvimento de liberdades.

Expostas as circunstâncias teóricas, é possível afirmar que o acesso a recursos financeiros não garante a ampliação de liberdades, mas a falta deles impede seu acesso a elas. Assim, crescimento econômico de regiões e aumento de renda sustentam algum progresso, mas não necessariamente o desenvolvimento como liberdade, mesmo naqueles casos em que o sujeito acumula recursos. É o que percebemos quando focamos nos dados das três cidades estudadas aqui, em que os dados financeiros são fortes, mas se contrapõem aos dados sociais. Pinheiro (2012, p. 13) escreve que "o fim último do desenvolvimento, o bem das pessoas, é associado à liberdade, isto é, à potência pessoal de conseguir a vida que se deseja racionalmente". A busca pela existência que se deseja como pessoa é marcada pela capacidade de o agente usufruir seu poder e autonomia em face das condições da vida. Fatores como fome, violência e pobreza funcionam como "fontes de privação de liberdade".

Sendo assim, demonstrada nossa opção conceitual para as discussões sobre o processo de urbanização brasileira e particularmente da Amazônia, a partir da referenciação nas cidades médias aqui compreendidas como cidades de comando regional e hibridização da qualidade de vida, bem como a adoção do conceito de desenvolvimento na perspectiva de Amartya Sen, apresentaremos a metodologia e passaremos a discutir o crescimento urbano na Amazônia Oriental e a caracterizar as três cidades objeto deste estudo: Araguaína - TO, Marabá - PA e Imperatriz MA.

\section{Aspectos metodológicos}

Através de trabalho descritivo-analítico levantamos proposições demonstrando que as três cidades possuem características semelhantes quanto ao crescimento econômico pujante, no entanto, com relação a qualidade de vida que envolvem aspectos como saneamento básico, segurança e desigualdades sociais ficam a desejar. Para Fontelles (2009, et al) a abordagem descritivo-analítico compõe o quadro de abordagem quantitativa permitindo expressar o fenômeno com dados numéricos, garantindo precisão e confiabilidade, a partir da descrição e mapeamento de fatos. Por sua vez, o trabalho analítico propõe se debruçar sobre os dados descritivos a fim de provocar reflexões acerca de determinados fenômenos.

Para o cumprimento da proposta descritivo-analítico trabalhou-se, por um lado, com dados secundários, referentes às três cidades, extraídos de bases como IBGE-cidades, , Atlas do Desenvolvimento Humano, Instituto Trata Brasil, IPEADATA e Comex Stat referentes a crescimento demográfico, exportações, IDH, PIB, homicídios, Cadastro Único, Programa Bolsa Família, acesso à água, à coleta e ao tratamento de esgoto; e por outro, da revisão de literatura bibliográfica e apoio em informações do Ministério do Planejamento e no documento REGIC (IBGE, 2020).

O trabalho analítico compreensivo foi costurado ao longo das duas próximas partes do texto, sendo a primeira contextualização e descrição da potência econômica das cidades e a segunda parte a demonstração das vulnerabilidades sociais. Os dados serviram de base para a análise teórico-analítica. 


\section{Araguaína, Imperatriz e Marabá: crescimento urbano na Amazônia Oriental}

Johnson (1982, 1999) e Bishop e Payne (2018), respectivamente, propõem e revisitam discussões em torno do estado desenvolvimentista. Em sua origem, a discussão parte da contextualização de processos decisórios que levaram a determinadas práticas nas esferas político-econômicas no Japão e Coréia do Sul que resultaram em desenvolvimento econômico a partir da industrialização. "One of my main purposes in introducing the idea of the "capitalist developmental state" into a history of modern japanese industrial policy was to go beyond the contrast between the American and Soviet economies" (JOHNSON, 1999, p. 32).

Considerando o contexto de início da proposição interpretativa ao questionamento acerca da eficácia de adoção da mesma perspectiva em países portadores de variáveis distintas daquelas observadas para os países orientais, Bishop e Payne estabelecem, quase duas décadas após Johnson, a seguinte interpretação:

\footnotetext{
First, it is not clear that the idea travels as easily as we might think across time and space. The original developmental states of East Asia (Japan and the 'Tigers' of Korea, Hong Kong, Singapore and Taiwan) were in many ways unique, and they all developed rapidly together in a particular geopolitical climate, and often with huge amounts of US aid. They were different to the early developers, and also different to those that have come since. That the label is now applied - whether loosely or tightly - to a vast array of countries as diverse as Indonesia, Brazil, Mozambique, Mauritius and Botswana (amongst many others) suggests that it may have lost a degree of comparative analytical purchase. Moreover, it is not clear whether any country, let alone all countries, can replicate the kinds of transformations that occurred in East Asia in the 1970s in the contemporary era of global value chain-driven globalisation (BISHOP; PAYNE, 2018, p. 3).
}

Tanto no que diz respeito ao emprego contemporâneo da proposta de desenvolvimento quanto acerca de sua origem no início da década de 70 , questionase se o contexto e o suporte econômicos de origem externa ausentes em outras espacialidades e temporalidades resultariam em industrialização e aumento dos indicadores econômicos em proporções similares àquelas observadas na situação de origem do debate.

A discussão acima, trazida ao contexto brasileiro, nos permite compreendêla como um dos referenciais de sustentação de nossa proposta interpretativa: as imprecisões na dinamização do chamado desenvolvimentismo propiciaram a estruturação de cidades de comando regional dinâmicas em economia e demografia, mas incapazes de propiciar desenvolvimento social e regional por não auxiliar na expansão das liberdades substantivas. Perissinotto (2014), ao discutir a burocracia necessária à produção de desenvolvimento econômico e industrialização, ressalta a fragilidade de relação existente entre o Estado brasileiro das décadas de 1970 e 1980 e os agentes sociais, de tipologias diversas, presentes e atuantes na região da Amazônia Legal na qual localizam-se as cidades apresentadas. Ausência de variáveis endógenas é resultado daquilo que o autor supracitado 
denomina de "insulamento" e "isolamento" entre as propostas implementadas na região e as dinâmicas regionais preexistentes às quais seriam trazidos os benefícios.

A ausência das variáveis burocracia coerente e inserção social torna-se, portanto, agente constitutivo de sustentação de nossa proposta interpretativa para as três cidades em questão. Analisadas enquanto resultado de uma série de políticas de concepção desenvolvimentista, o que se observa, a partir dos dados expostos no próximo tópico deste texto, é que as três cidades são marcos para o desenvolvimento regional desigual, resultante de ações capazes de proporcionar e potencializar crescimento econômico e, em proporções ainda mais significativas, desigualdades sociais. Cabe ressaltar, ainda, que o desenvolvimentismo aplicado à América Latina e mais especificamente ao Brasil será compreendido, para além das discussões apresentadas até aqui, como um "fenômeno na esfera do pensamento" e um "conjunto de práticas históricas de política econômica" experienciados em países da América Latina a partir das proposições da Comissão Econômica para a América Latina e o Caribe - CEPAL (ROTTA; REIS, 2018). Trata-se, portanto, de fenômeno circunscrito a determinada temporalidade com desdobramentos nas ciências econômicas por meio da estruturação, décadas adiante, do chamado neodesenvolvimentismo e do social-desenvolvimentismo.

Um conjunto de medidas na esfera político-administrativa nacional foi tomado a partir do final da década de 1950, reverberando diretamente na estruturação das dinâmicas das cidades em torno das quais discutimos. Ressalta-se que o objetivo primeiro desse conjunto de ações foi a chamada integração da Amazônia aos cenários produtivo e consumidor nacionais. O quadro abaixo representa uma síntese de tais ações e demonstra suas respectivas evoluções em suas temporalidades que, para fins de constituição do quadro, foram recortadas em seus aspectos relacionais mais próximos das cidades abordadas.

Quadro 1 - Iniciativas estatais para o desenvolvimento da Amazônia

\begin{tabular}{|c|c|c|}
\hline Período & Programa & Ações \\
\hline 1960-1975 & $\begin{array}{c}\text { Construção da rodovia Belém- } \\
\text { Brasília; Programa de } \\
\text { Integração Nacional (PIN) }\end{array}$ & $\begin{array}{c}\text { Inaugura-se o rodoviarismo } \\
\text { na Amazônia. São } \\
\text { projetadas as rodovias } \\
\text { Transamazônica e Belém - } \\
\text { Brasília }\end{array}$ \\
\hline 1974 a 1980 & Programa Polamazônia & $\begin{array}{l}\text { Proposição de polos } \\
\text { considerados prioritários: } \\
\text { Carajás, Altamira e Pré- } \\
\text { Amazônia Maranhense }\end{array}$ \\
\hline 1980 & $\begin{array}{l}\text { Programa Grande Carajás } \\
\text { (PGC) }\end{array}$ & $\begin{array}{c}\text { Estabelecimento de } \\
\text { indústria de mineração na } \\
\text { Serra dos Carajás }\end{array}$ \\
\hline 1990 & $\begin{array}{c}\text { Programa-piloto para } \\
\text { Proteção das Florestas } \\
\text { Tropicais do Brasil (PPG 7) }\end{array}$ & $\begin{array}{l}\text { Parceria do Ministério do } \\
\text { Meio Ambiente com a } \\
\text { sociedade civil brasileira, o } \\
\text { Banco Mundial e os países } \\
\text { do G-7. Proposição de } \\
\text { projetos para o uso }\end{array}$ \\
\hline
\end{tabular}




\begin{tabular}{|c|c|c|}
\hline & Avança Brasil & $\begin{array}{c}\text { sustentável dos recursos } \\
\text { naturais e redução de } \\
\text { desmatamento }\end{array}$ \\
\hline $2000-2003$ & $\begin{array}{c}\text { Construção de } \\
\text { hidroelétricas com eclusas } \\
\text { ao longo do rio Tocantins } \\
\text { impulsionando o estado de } \\
\text { mesmo nome a transformar- } \\
\text { se no novo “Eldorado" das } \\
\text { atividades agrícolas. }\end{array}$ \\
\hline $2008-2011$ & $\begin{array}{c}\text { Produção de desigualdades } \\
\text { Programa de Promoção da } \\
\text { Sustentabilidade de Espaços } \\
\text { Sub-regionais }\end{array}$ & $\begin{array}{c}\text { territórios definidos, por } \\
\text { meio de ações endógenas e } \\
\text { fortalecimento produtivo. }\end{array}$ \\
\hline
\end{tabular}

Fonte: Elaborado pelos autores a partir de informações do Ministério do Planejamento.

As ações de Estado levaram a um desenvolvimentismo a região estudada, e três fatores iniciais transformaram-se em critério de seleção para a abordagem dessas três cidades: o primeiro deles, a questão demográfica. Observam-se os seguintes contingentes populacionais estimados para o ano de 2020 para cada uma delas de acordo com o IBGE: Marabá, 283.542 habitantes, Imperatriz, 259.337 habitantes, e Araguaína, 183.381 habitantes. Desde o ano de 2010, a cidade de Araguaína cresceu 21,86\%, enquanto o estado do Tocantins $14,94 \%$; a cidade de Marabá, 21,34\%, ficando a frente do Pará com índice de 14,63\%; ambas acima da média nacional de crescimento demográfico, que é de $11,00 \%$. As duas cidades alavancaram crescimento demográfico acima da média de seus estados e do Brasil, demonstrando capacidade de atratividade e se configurando como polo migratório para a busca de melhores condições de vida. A cidade de Imperatriz aumentou seu quantitativo populacional em 4,78\% (IBGE, 2020), enquanto o Maranhão cresceu $8,21 \%$.

O segundo fator diz respeito à posição geográfica: forma-se entre as três cidades um triangulo com vértices semi-equidistantes (ver mapa 1), localizadas na regionalização da Amazônia compreendida por Becker como Macrorregião de Povoamento Consolidado ou Amazônia Oriental, portadora das seguintes características, apontadas por Trindade Júnior (2013):

1 - Abarca grandes extensões de cerrado do Mato Grosso, Tocantins, Maranhão e áreas desmatadas do sudeste do Pará, de Rondônia e sul do Acre;

2 - Mais altas taxas de renda per capita e IDH da região;

3 - Representa o cerne da economia regional, integrado ao tecido produtivo nacional e onde a produção predomina sobre a conservação. 
Mapa 1 - Localização e distâncias entre Araguaína, Imperatriz e Marabá

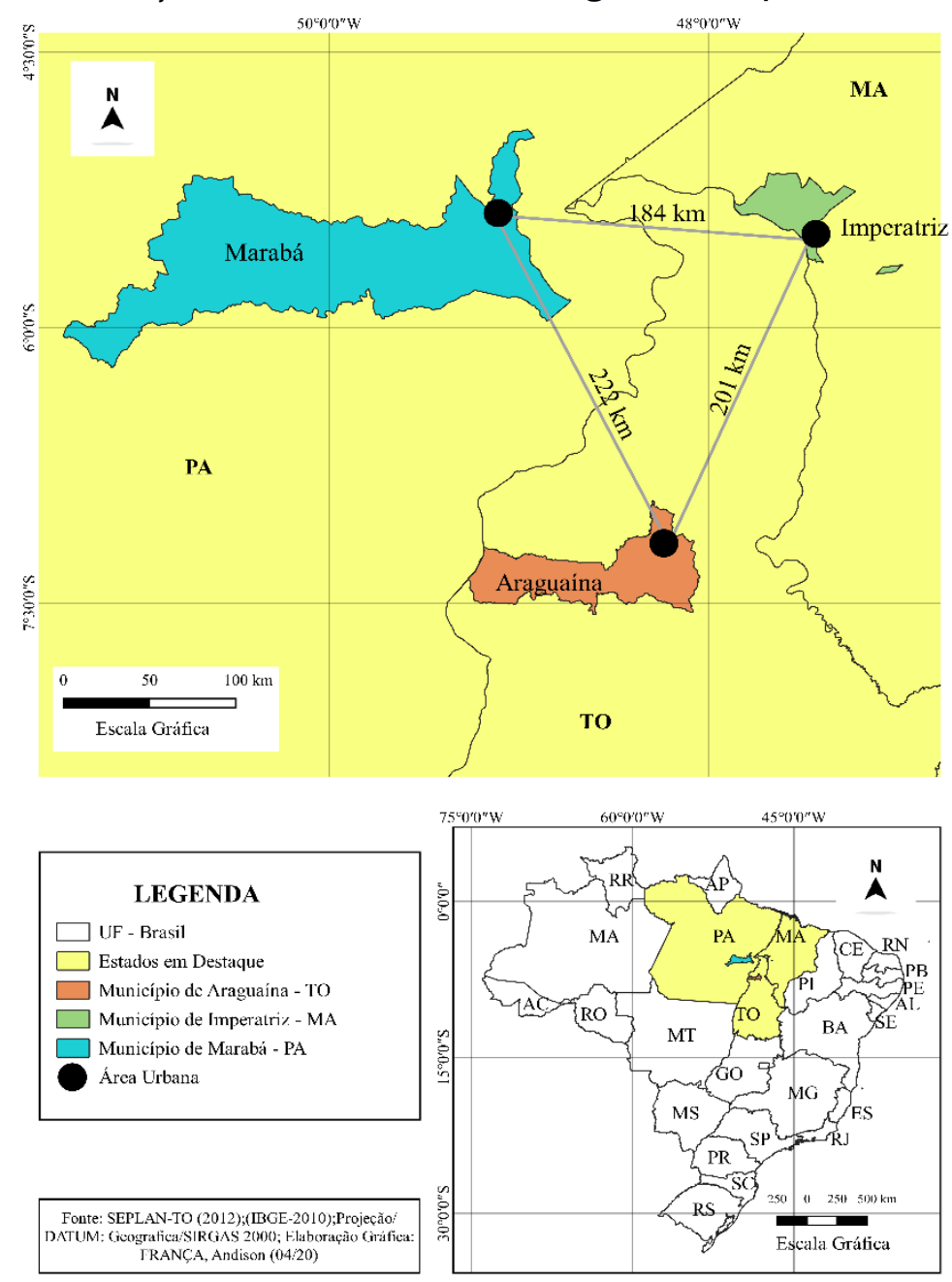

O terceiro fator diz respeito à literatura que discute cidades médias na Amazônia, ou aspectos particulares de cada uma das cidades supracitadas. Ao discutir a centralidade do município de Araguaína e sua região de influência imediata, Gomes Júnior e Nascimento (2014) mencionam elos de origem econômica e social com as cidades de Marabá e Imperatriz. Nogueira (2013) problematiza Imperatriz como ponto de apoio ao desenvolvimento amazônico e menciona que o asfaltamento da Belém-Brasília no ano de 1974 (ver mapa 2) possibilita a dinâmica de interiorização da urbanização na Amazônia Oriental com implicações para Marabá e Araguaína. 
Mapa 2 - Rodovias estaduais e federais entre Araguaína, Imperatriz e Marabá

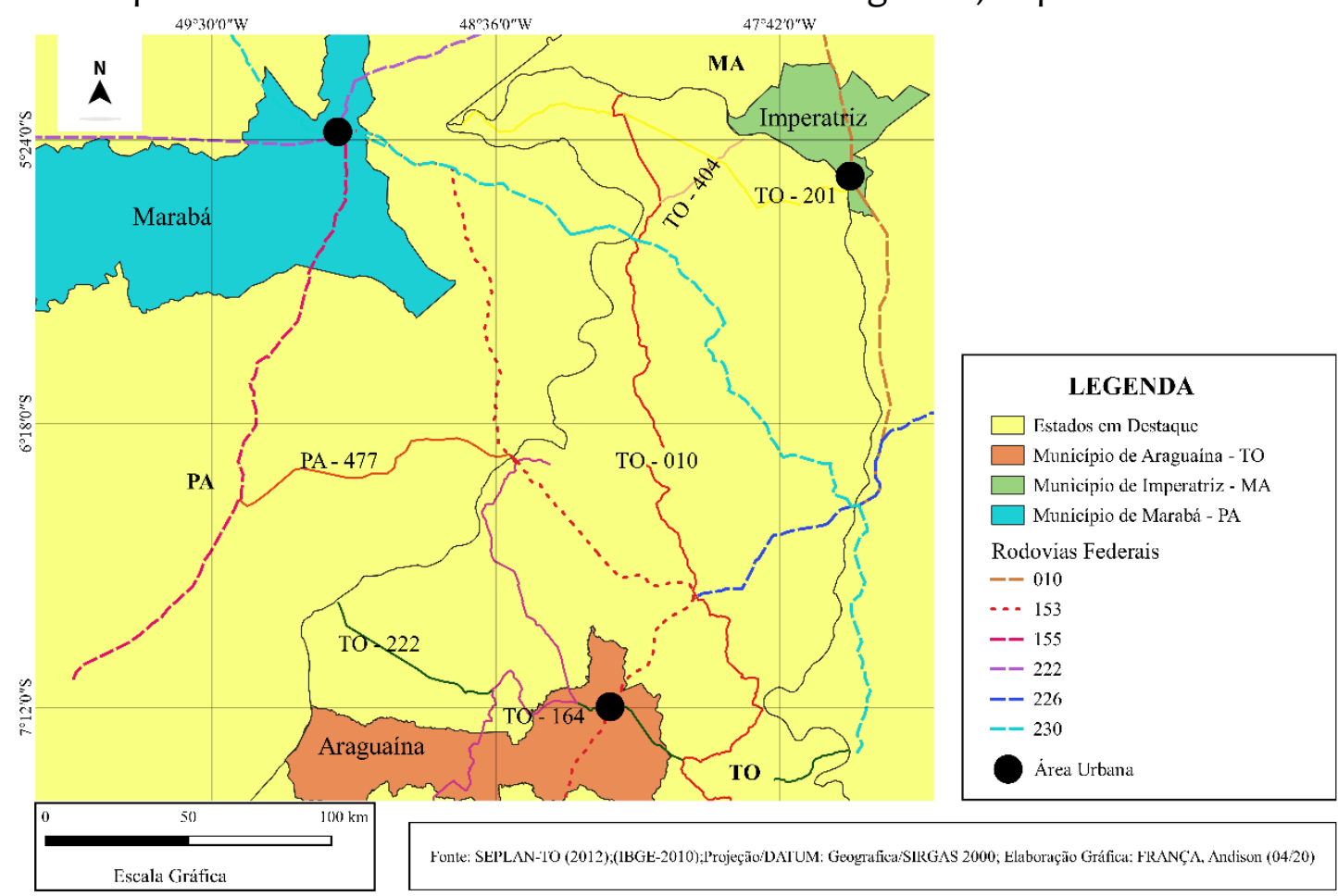

Araújo (2016), ao pesquisar a região de influência de Imperatriz, ressalta que, segundo o REGIC (2008), as regiões imediatas são compotas por outras duas capitais regionais C: Araguaína e Marabá. A pesquisa Regiões de Influência das Cidades REGIC, desenvolvida pelo IBGE, objetiva demonstrar a hierarquia dos centros urbanos brasileiros bem como suas capitais regionais e respectivas áreas de influência. A partir de 2008, há o mesmo status para as três cidades. Situadas na Amazônia Legal, são resultado também de propostas do chamado desenvolvimentismo. No mapa 3 é possível verificar a área de influência das localidades e perceber que as três estabelecem divisas entre si. 
Mapa 3 - Área de influência de Araguaína, Imperatriz e Marabá
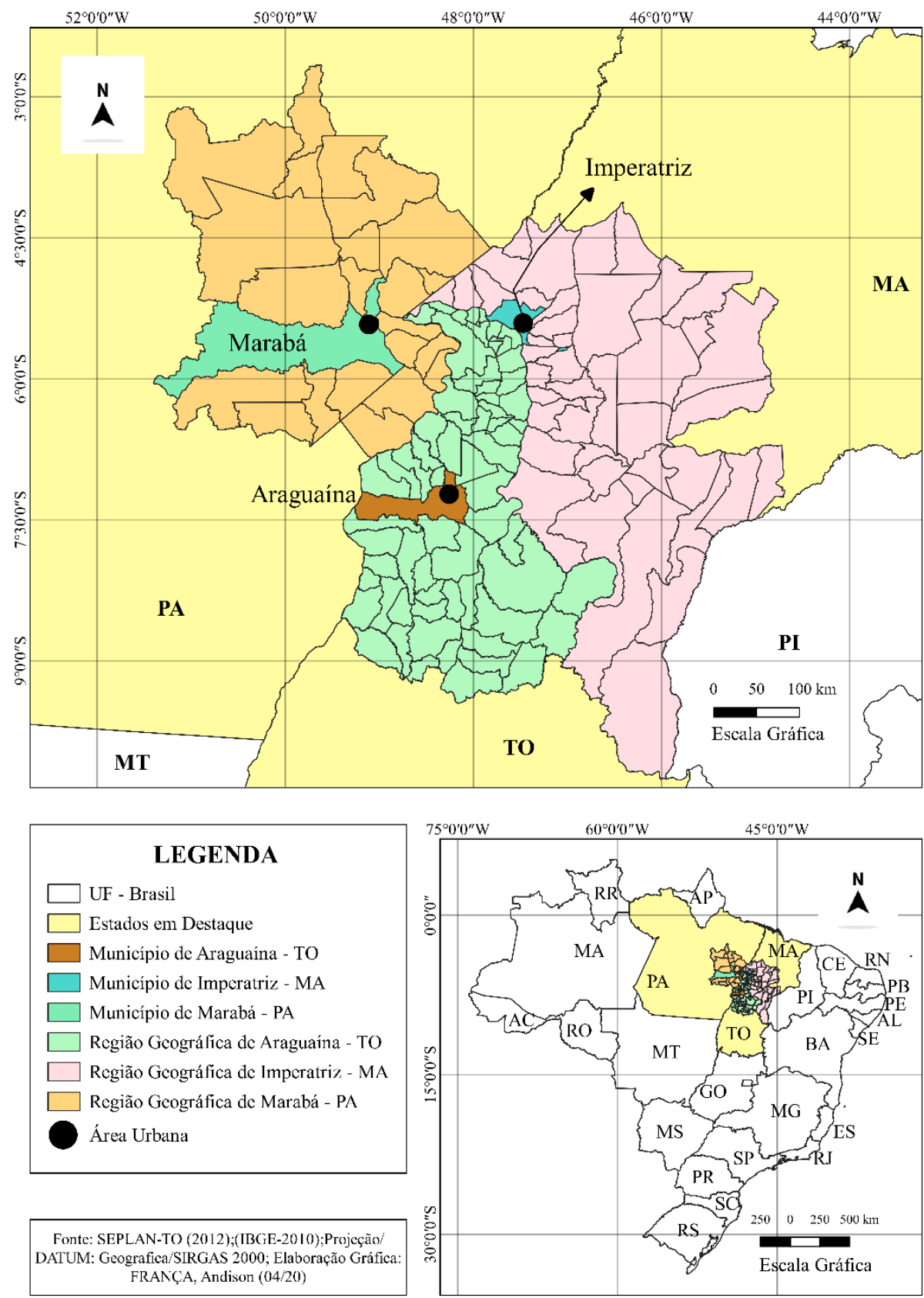

Nesse sentido, o entendimento da dinamicidade das cidades objeto deste estudo permite referenciação no que se entende como estado desenvolvimentista ou aquela que pode ser entendida como configuração político-administrativa capaz de levar a cabo o chamado desenvolvimentismo.

Perissinotto (2014) discute o estado desenvolvimentista observando suas especificidades, proposições e ações numa perspectiva comparativa entre o Brasil e a Argentina. O diálogo com essa perspectiva de desenvolvimento se faz necessário ao propósito deste trabalho, demonstrar como as cidades em questão apresentaram crescimento demográfico acima da média nacional, crescimento econômico dinâmico, elevação de índices de desenvolvimento humano e de vulnerabilidade social acima de suas regiões e estados. Na tabela 1 verificamos que as três localidades têm posição privilegiada diante de sua microrregião e ocupam 
papel de destaque no coletivo de seus estados, além de possuírem IDH considerados medianos.

Tabela 1 - Posição relativa da população e IDH de Araguaína, Imperatriz e Marabá

\begin{tabular}{llll}
\hline \multicolumn{1}{c}{ Cidades } & \multicolumn{1}{c}{$\begin{array}{c}\text { Posição da } \\
\text { população na } \\
\text { microrregião }\end{array}$} & $\begin{array}{c}\text { Posição da } \\
\text { população no } \\
\text { estado }\end{array}$ & IDH \\
\hline Araguaína & $\begin{array}{l}1^{\circ} \text { em } 17 \\
\text { municípios }\end{array}$ & $\begin{array}{l}2^{\circ} \text { em } 139 \\
\text { municípios }\end{array}$ & 0,752 \\
Imperatriz & $1^{\circ}$ em 5 & $2^{\circ}$ em 217 & 0,731 \\
& municípios & $\begin{array}{l}\text { municípios } \\
10^{\circ} \text { em } 144\end{array}$ & 0,668 \\
Marabá & $1^{\circ}$ em 16 & municípios & \\
& municípios & 2010).
\end{tabular}

Com atributos como alto crescimento demográfico, polos de influência e de crescimento econômico, índice mediano de desenvolvimento humano numa região marcada por números de elevada vulnerabilidade social, as cidades em questão à primeira vista podem ser interpretadas como fórmula de sucesso da política desenvolvimentista de Estado. Em termos comparativos podemos afirmar que o IDH de Araguaína é similar ao de seu estado (0,756 - Tocantins), o de Imperatriz é mais alto que do Maranhão (0,683), apesar de ambos estarem num patamar considerado mediano, somente o de Marabá é abaixo de seu estado (0,755 - Pará), mas ambos encontram-se também num patamar mediano.

Para auxiliar na análise, expomos o gráfico 2 mostrando os números de exportação para o período de 2010 a 2019:

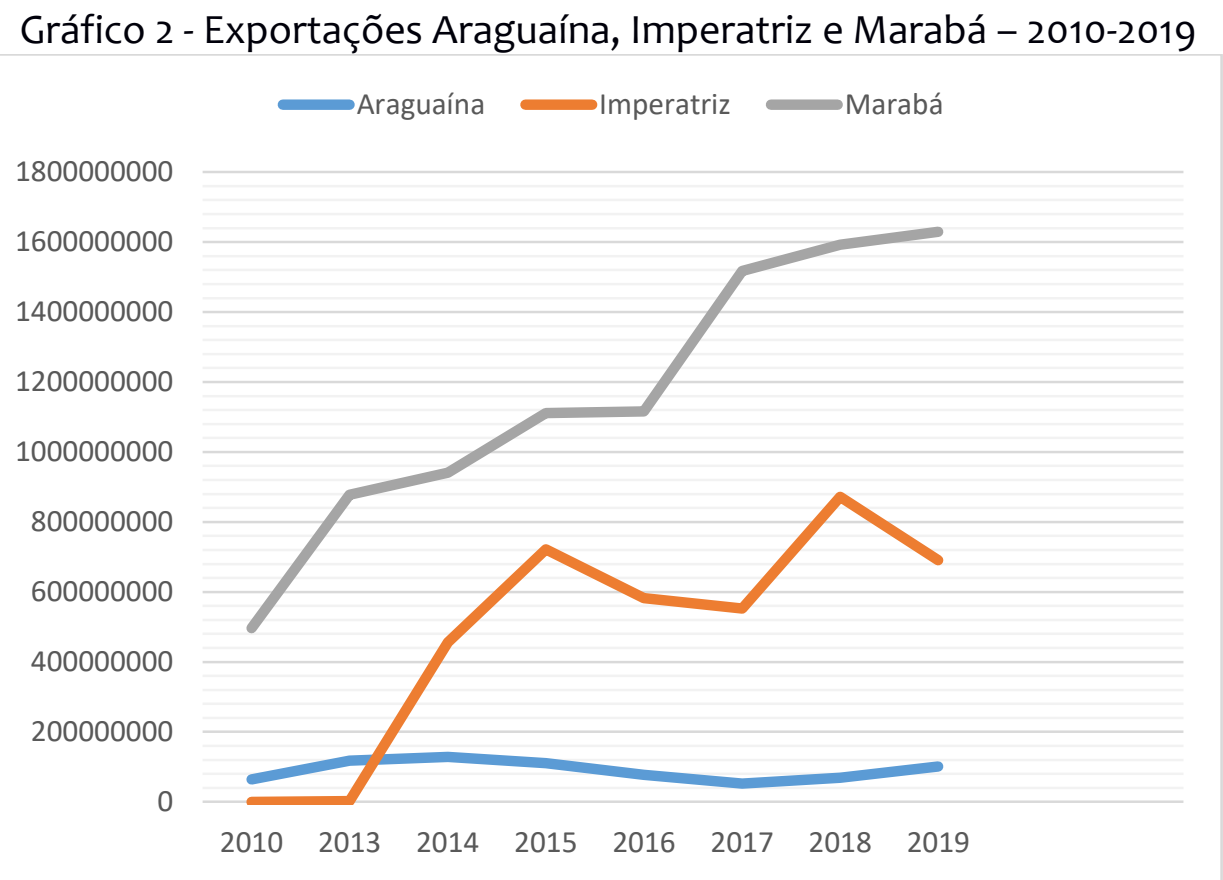

Fonte: Elaborado pelos autores a partir de dados do Comex Stat. 
Como comparação observamos em dados do MAPA de 2019 que o ponto mais alto de exportação no Brasil ocorre em 2013, sendo que de 2010 até essa data houve um aumento no país de 30,9\% nas exportações. De 2013 a 2016 houve uma queda de 13,6\%, com retomada até 2018 em torno de 18\% e pequena queda novamente em 2019 de 4\% (SNA, 2020). Por sua vez Marabá é pujante em exportações e pouco sente as variações econômico-políticas do país, apresentando crescimento ano a ano e no mesmo corte (2010-2013) houve um crescimento de $76,8 \%$, muito acima dos 13,6\% de crescimento nacional. De 2013 a 2016 um aumento de $27 \%$, com pequena estagnação entre 2015 e 2016 e continua a crescer até 2019 na taxa de $46 \%$. Tal desempenho ocorre muito em função de suas altas taxas de retirada de minérios da região.

A cidade de Araguaína em comparação com o Brasil no recorte 2010-2013 tem um aumento de $83 \%$ nas exportações, mas entre 2013 e 2016 tem uma queda de $34 \%$, com retomada entre 2016 e 2019 em 30.8\%. Imperatriz, por sua vez, entre 2010 e 2013 tem um crescimento de mais de 5000\%, período em que a empresa Suzano Celulose se instala na cidades; entre 2013 e 2016 ocorre outro boom de mais de $32.300 \%$ nas exportações e, apesar de uma pequena queda nos anos de crise financeira, entre 2016 e 2019 ocorre um aumento de 18\%. Com ressalvas as características de cada uma, é possível com tais dados afirmar que as três cidades são representativas de alto padrão de crescimento em importações e quando comparadas ao Brasil seus números são significativamente maiores.

Elas conseguem ter números expressivos de exportação, muito em razão de serem fronteira agrícola-mineral do país. Tal crescimento e atratividade econômica muitas vezes ocorre em detrimento de desenvolvimento regional e socialmente homogêneo para suas populações. Os números aumentam, a renda cresce:

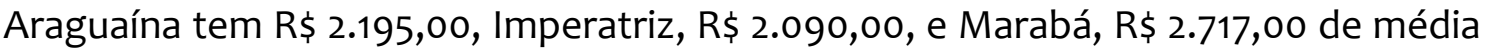
de renda per capita, enquanto a média brasileira é de $\mathrm{R} \$ 1.439,00$, todos para o ano de 2020. Entretanto, as desigualdades são alarmantes, e a riqueza econômica nem sempre se manifesta em qualidade de vida, em garantia das liberdades instrumentais e, menos ainda, das liberdades substantivas. É o que veremos a seguir.

\section{Fragilidades nas liberdades instrumentais e substantivas}

As liberdades instrumentais são aquelas que servem de ferramentas para que se alcance as liberdades substantivas; assim, as condições básicas de vida (liberdades instrumentais) garantem o acesso à expansão das capacidades (liberdades substantivas). Sen (2010) compreende cinco tipos de liberdades instrumentais: liberdade política, oportunidades econômicas e sociais, garantias de transparência e proteção social. Essas abarcam desde o acesso à alimentação e à saúde, às possibilidades de relações saudáveis e escolhas. Observamos que nas localidades estudadas existe uma precarização das condições de vida que pode ser observada em dados oficiais dos números de homicídios, famílias no Cadúnico e beneficiários do Programa Bolsa Família. Acreditamos que tais dados permitem dizer que as condições básicas de vida estão fragilizadas pelo não acesso a recursos financeiros e à saúde e pela exposição elevada à violência. 
Começaremos pelo Cadúnico. Criado em 2003, o Cadastro Único é um importante instrumento do governo federal para caracterizar as famílias de baixa renda; é por meio dele que se tem acesso a programas importantes, tais como o Programa Minha Casa Minha Vida, Tarifa social de energia elétrica, Bolsa Verde, entre outros (BRASIL, 2020).

Entre todos os benefícios que fazem parte do escopo dessa ferramenta de acesso voluntário temos ainda o Programa Bolsa Família (PBF), importante programa de transferência de renda às famílias em situação de pobreza e extrema pobreza. Essas famílias, quando se encaixam no perfil socioeconômico estabelecido pelo PBF, recebem benefícios variados com o objetivo de superar sua situação de vulnerabilidade social (BRASIL, 2019).

Nesse sentido, apresentamos os dados gerais que concernem ao Cadúnico dos municípios de Araguaína-TO e Marabá-PA, localizados na região Norte do Brasil, e Imperatriz-MA, situada na região Nordeste, todas inseridas na Amazônia Legal Descreve-se que essas duas regiões juntas destacam-se pelo maior número de famílias recebedoras de uma política pública de transferência de renda, o PBF, totalizando, até dezembro de 2019, 8.466.634 famílias.

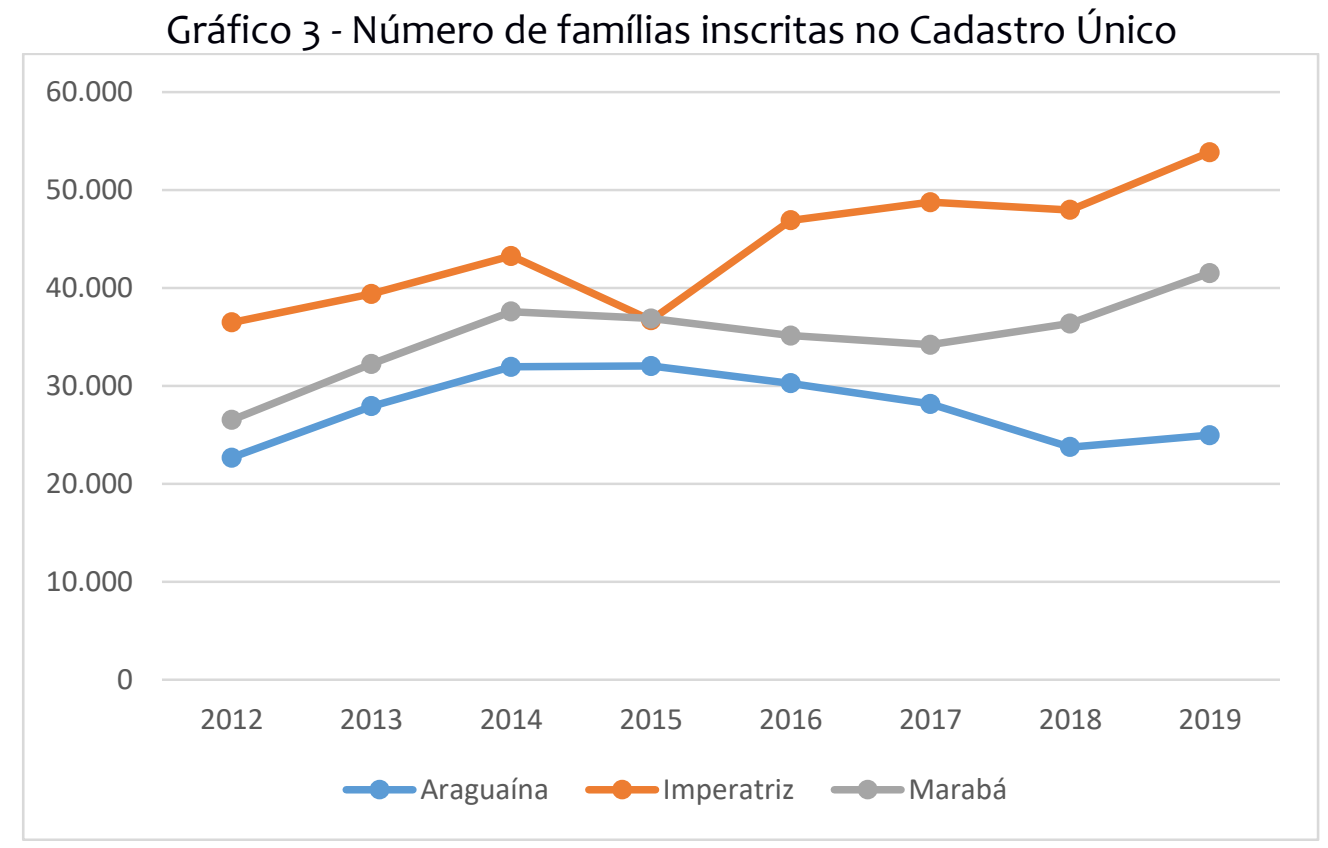

Fonte: Adaptado de https://aplicacoes.mds.gov.br/. Acesso em: 20 abr. 2020.

No gráfico 3, verificamos que no período de 2012 a 2019 ocorre um crescimento no número de pessoas inscritas no Cadúnico nas três localidades, demonstrando um aumento na vulnerabilidade social. O nível de fragilidade econômica, pode ser visualizado na tabela 2, que demonstra o número de famílias por renda per capita. 
Tabela 2 - Número de famílias inscritas no Cadastro Único em Araguaína, Imperatriz e Marabá, dez/2019

\begin{tabular}{|c|c|c|}
\hline Cidades & N.o Famílias & Renda per capta \\
\hline \multirow{5}{*}{ Araguaína } & 2.099 & Até $\mathrm{R} \$ 89,00$ \\
\hline & 6.590 & $\mathrm{R} \$ 89,01$ até $\mathrm{R} \$ 178,00$ \\
\hline & 9.927 & $\mathrm{R} \$ 178,01$ até $1 / 2$ salário mín. \\
\hline & 6.353 & Acima de 1/2 salário mín. \\
\hline & 24.969 & Total \\
\hline \multirow{5}{*}{ Imperatriz } & 11.273 & Até $R \$ 89,00$ \\
\hline & 6.774 & $\mathrm{R} \$ 89,01$ até $\mathrm{R} \$ 178,00$ \\
\hline & 23.339 & $\mathrm{R} \$ 178,01$ até $1 / 2$ salário mín. \\
\hline & 12.463 & Acima de 1/2 salário mín. \\
\hline & 53.849 & Total \\
\hline \multirow{5}{*}{ Marabá } & 10.632 & Até $R \$ 89,00$ \\
\hline & 8.949 & $\mathrm{R} \$ 89,01$ até $\mathrm{R} \$ 178,00$ \\
\hline & 11.953 & $\mathrm{R} \$ 178,01$ até $1 / 2$ salário mín. \\
\hline & 9.984 & Acima de 1/2 salário mín. \\
\hline & 41.518 & Total \\
\hline
\end{tabular}

Fonte: Adaptado de: https://aplicacoes.mds.gov.br/. Acesso em: 20 abr. 2020.

Enquanto o número de inscritos no Cadúnico aumentou, demonstrando a necessidade de melhorar a proteção social dessa população, o número de beneficiários do PBF diminuiu, conforme vemos no gráfico a seguir: 
Gráfico 1 - Número de beneficiários do Programa Bolsa Família - base mês de dezembro de 2010-2019

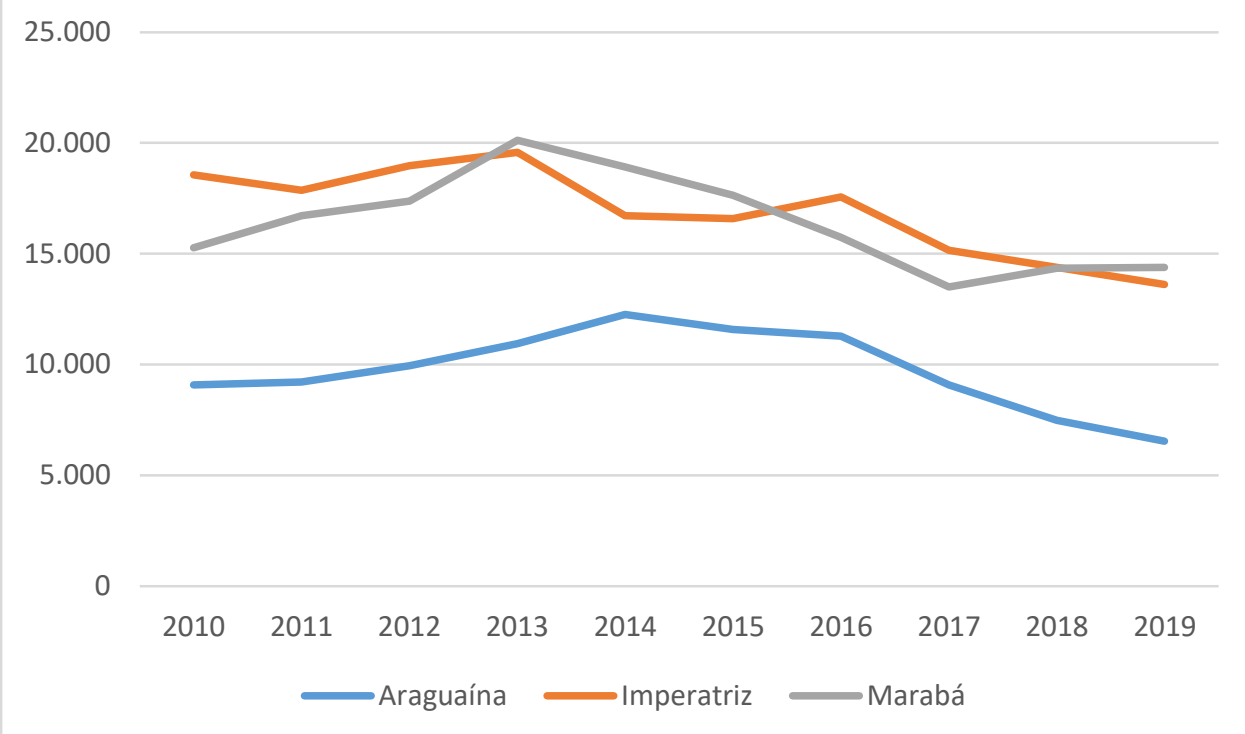

Fonte: “Adaptado de" https://aplicacoes.mds.gov.br. Acesso em 20/04/2020

Destarte, Teles (2020) demonstra em seu trabalho que em Araguaína, por dificuldades na gestão em 2019 o orçamento destinado ao Programa Bolsa Família foi executado parcialmente e ficou abaixo da meta de atendimento, o que foi apontado em relatório do Ministério do Desenvolvimento Social. Cabe retomar aqui a proporcionalidade de aumento de exportações das três cidades e o aumento de pessoas no CAdúnico, demonstrando que de alguma forma a equação não se fecha, em outros termos, não percebemos o direcionamento do crescimento econômico em prol de uma parcela da população.

Além de acessar parcos recursos financeiros, o que dificulta a ampliação das capacidades substantivas, a população está sujeita a um alto índice de violência, conforme o gráfico de número de homicídios no período. 
Gráfico 2 - Números de homicídios Araguaína, Imperatriz e Marabá - 2010-2017

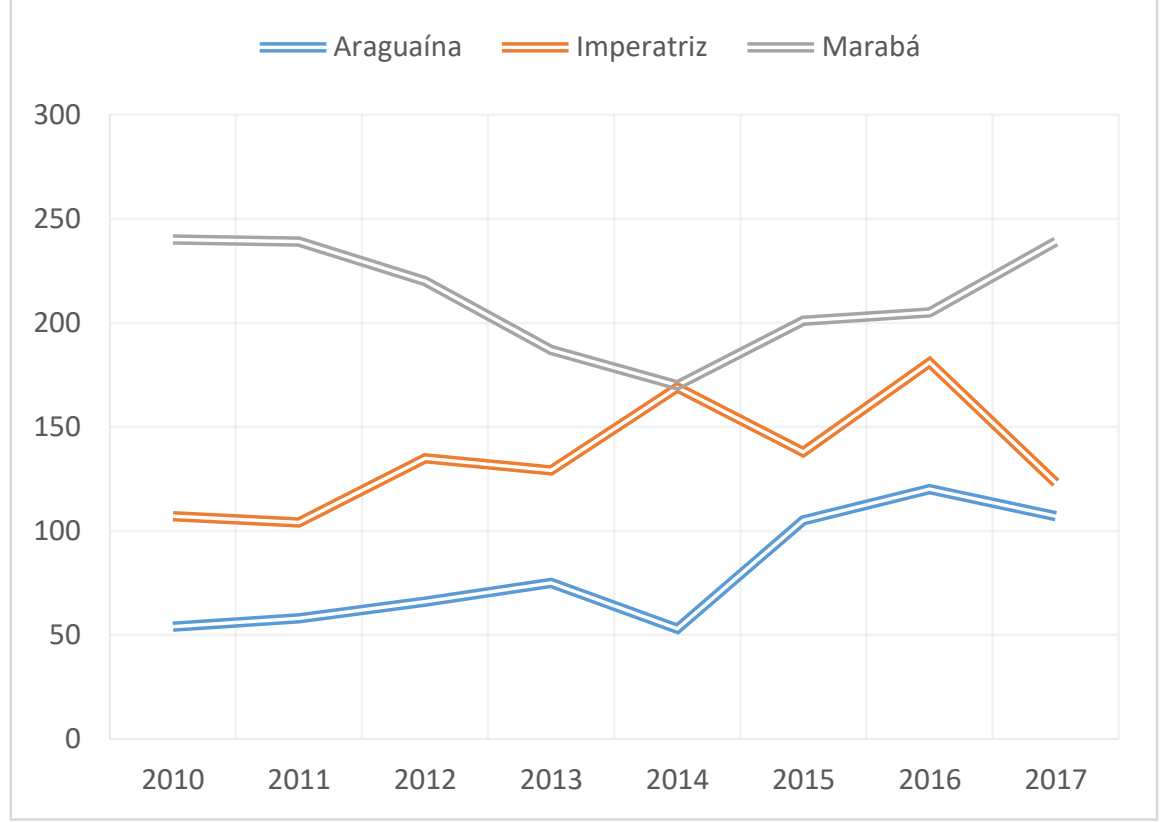

Fonte: Elaborado pelos autores a partir de IPEA/Atlas da Violência.

Cabe reforçar que, segundo o Atlas da Violência (IPEA, 2019), com base nos dados de 2017, a média nacional de homicídios por cem mil habitantes é de 31,6, podendo variar da mais baixa, em São Paulo, de 10,3, à mais alta, no Rio Grande do Norte, de 62,8. O índice de homicídios por cem mil habitantes para Araguaína é de 70,5, para Imperatriz é de 71,7 e para Marabá é de 87,7. As três cidades aparecem entre as cem mais violentas do Brasil, estando Araguaína situada na $34^{\text {a }}$ posição,

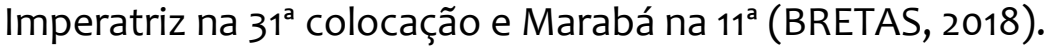

Ainda para corroborar com a tese de que as localidades estudadas crescem e se tornam polos de atração financeira, mas ainda atuam de maneira insuficiente para proporcionar o acesso às liberdades substantivas, expomos dados disponíveis no site da Organização Trata Brasil referentes à coleta de esgoto e à água tratada:

Tabela 2 - Acesso à água tratada, à coleta e ao tratamento de esgoto

\begin{tabular}{lllll}
\hline Cidades & Araguaína & Imperatriz & Marabá & Brasil \\
\hline $\begin{array}{l}\text { População } \\
\text { sem Acesso à } \\
\text { água }\end{array}$ & $3,6 \%$ & $5,2 \%$ & $65,8 \%$ & $16,4 \%$ \\
\hline $\begin{array}{l}\text { População } \\
\text { sem acesso à } \\
\text { coleta de } \\
\text { esgoto de }\end{array}$ & $66,7 \%$ & $99,4 \%$ & $46,9 \%$ \\
\hline $\begin{array}{l}\text { Índice de } \\
\text { esgoto } \\
\text { tratado }\end{array}$ & & & \\
\hline
\end{tabular}

Fonte: Adaptado de https://www.painelsaneamento.org.br/localidade/index?id=0 Trata Brasil com base IBGE/2018. Acesso em: 27 abr. 2020. 
O acesso à água tratada, à coleta e ao tratamento de esgoto diz muito sobre o nível de desenvolvimento de um país, uma vez que se trata de referência básica para análise da qualidade de vida de uma população e inferência de questões como mortalidade infantil, acesso à saúde, educação, valorização imobiliária, renda do trabalhador, entre outras. Os dados de Araguaína, Imperatriz e Marabá sobre coleta e tratamento de esgoto são inversamente proporcionais ao crescimento econômico e à atratividade dessas cidades. Em Marabá, a situação é ainda mais precária quando se adiciona o componente de que $65,8 \%$ da população não têm acesso à água tratada.

Os dados apresentados sobre a população inscrita no Cadúnico, beneficiários do Bolsa Família, número de homicídios e acesso à água tratada, à coleta e ao tratamento de esgoto demonstram uma região ainda bastante fragilizada em relação a determinados marcadores sociais e que em decorrência disso ainda privilegia o acúmulo de capital em detrimento da qualidade de vida.

A contraposição dos dados econômicos aos sociais, em termos de crescimento de exportação, PIB e renda per capita evidenciam o quanto a visão de desenvolvimento é voltada somente para o acúmulo de capital, revertendo muito pouco para a estruturação social em termos de acesso às liberdades instrumentais e consequentemente as substantivas.

\section{Considerações Finais}

O texto apresentado visou demonstrar teoricamente que as cidades médias são aquelas que funcionam como protagonistas para uma região mantendo como elementos centrais o acesso a serviços típicos de cidades maiores e a qualidade de vida das cidades pequenas, além de apresentar as peculiaridades dessas na Amazônia brasileira. Debateu também como o desenvolvimentismo se aplicou ao Brasil e se desvirtuou na equação entre crescimento econômico e qualidade de vida, mostrando que se, por um lado, as cidades médias vêm ganhando espaço econômico, por outro, aspectos relativos ao acesso às liberdades substantivas se mostram ainda precários.

Para asseverar tal tese, apresentamos três cidades - Araguaína/TO, Imperatriz/MA e Marabá/PA, que por suas peculiaridades vêm demonstrando vocação para impulsionar uma região bastante abrangente, mas que para tanto carecem ainda de um olhar em duas frentes importantes: a primeira diz respeito à possibilidade e à necessidade de políticas públicas de interligação entre as três, o que deveria acontecer de maneira física - com a melhoria e duplicação de rodovias e de maneira administrativa, permitindo que as três formassem um bloco forte de acordos diante das negociações que se fizessem necessárias; a segunda refere-se a necessidade de compreensão do desenvolvimento regional incorporando os debates de ampliação das liberdades substantivas. Cabe ressaltar que os dados sociais apresentados se referem às liberdades instrumentais, visto que tem relação com as condições básicas de existência, sendo essas últimas condições necessárias para se estabelecer pontes para o desenvolvimento via liberdades substantivas.

Existe uma relação complexa e estreita entre acesso à renda e a liberdades; a primeira pode garantir a segunda e vice-versa, assim como a falta de liberdades substantivas pode impedir o acesso à renda. O contrário também se estabelece, de 
tal maneira que só é possível pensar o desenvolvimento se houver a capacidade de compreensão do quão interligados os fatores estão. Aumentar ano a ano as exportações ou a população comprova que uma parte do processo está em curso, contudo, dados irrisórios de aspectos básicos, como acesso à água e ao esgoto tratados e a exposição à violência, demonstram que a equação ainda não fecha.

Os dados nos mostram que devemos pensar qual o objetivo do desenvolvimento de um país ou de uma localidade; na lógica seniana só é possível aferir desenvolvimento se o ser humano for o objetivo primeiro e razão máxima dos procedimentos, o que parece não acontecer nas três cidades enunciadas.

\section{REFERÊNCIAS}

AMORIM FILHO, Oswaldo; SERRA, Rodrigo Valente. Evolução e perspectivas do papel das cidades médias no planejamento urbano e regional. In: ANDRADE, Thompson Almeida; SERRA, Rodrigo Valente (org.). Cidades médias brasileiras. Rio de Janeiro: IPEA, 2001. p. 1-34. Disponível em:

http://repositorio.ipea.gov.br/handle/11058/3081. Acesso em: 28 abr. 2020.

ARAÚJO, José Alencar Viana de. A região de influência de Imperatriz-MA: estudo da polarização de uma capital regional, destacando a regionalização dos serviços públicos de saúde. 2016. Dissertação (Mestrado em Desenvolvimento Urbano) Centro de Artes e Comunicação, Universidade Federal de Pernambuco, 2016.

BECKER, Bertha. Undoing myths: the Amazon - an urbanized forest. In: CLÜSENERGODT, M. C.; SACHS, I. (ed.). Brazilian perspectives on sustainable development for the Amazon region. Paris: UNESCO, 1995. p. 53-89.

BECKER, Bertha. A urbe amazônida. Rio de Janeiro: Garamond, 2013.

BELTRÃO, Jane Felipe; LACERDA, Paula Mendes. Amazônias em tempos contemporâneos: entre diversidades e adversidades. Rio de Janeiro: Mórula, 2017

BISHOP, Matthew L.; PAYNE, Anthony. Why revisit the developmental state?

Revisiting the developmental state. SPERI - Revisiting the developmental state, $\mathrm{n}$. 43, p. 2-4, fev. 2018.

BRASIL. Ministério do Desenvolvimento social. Manual do pesquisador: Programa Bolsa Família. Brasília: MDS, 2018. Disponível em:

https://aplicacoes.mds.gov.br/sagirmps/ferramentas/docs/manual_do_pesquisador gestao_bolsa_familia_semlogo.pdf. Acesso em: 18 nov. 2019.

BRASIL. Ministério do Desenvolvimento Social. Aplicações MDS. Disponível em: https://aplicacoes.mds.gov.br. Acesso em: 20 abr. 2020. 
BRASIL. Ministério da Educação. Coordenação de Aperfeiçoamento de Pessoal de Nível Superior. Documento de área: Planejamento Urbano e Regional/Demografia. Brasília: MEC/CAPES, 2019.

BRETAS, Valéria. As 100 cidades grandes e médias mais violentas do Brasil, segundo o IPEA. Exame, São Paulo, 15 jun. 2018. Disponível em:

https://exame.abril.com.br/brasil/as-100-cidades-grandes-e-medias-mais-violentasdo-brasil-segundo-o-ipea/. Acesso em: 25 abr. 2020.

FONTELLES, Mauro José; GARCIA, Marilda; HASEGAWA, Samantha; FONTELLES, Renata Garcia Simões. Metodologia de pesquisa científica: diretrizes para elaboração de um protocolo de pesquisa. Revista Paraense de Medicina. Vol 23, n. ${ }^{\circ}$, pp. 1-8, jul-set de 2009. Disponível https://pesquisa.bvsalud.org/portal/resource/pt/lil-588477. Acesso 30/08/2020.

GOMES JUNIOR, Evaldo; NASCIMENTO, Humberto Miranda. A centralidade do município de Araguaína - TO na Amazônia Oriental. In: SEMINÁRIO INTERNACIONAL RII, 13.; TALLER DE EDITORES RIER, 6., 2014, Salvador. Anais [... ]. Salvador, 01 a 04 de setembro de 2014. p. 1 a 15.

GONÇALVES, Carlos Walter Porto. Amazônia enquanto acumulação desigual de tempos: Uma contribuição para a ecologia política da região. Revista Crítica de Ciências Sociais, 107, pp. 63-90, Setembro 2015.

GONÇALVES, Carlos Walter Porto. Amazônia, Amazônias. São Paulo: Contexto, 2020 HURTIENNE, T. P. A dinâmica da ocupação da Amazônia: uma análise dos dados populacionais. In: COELHO, M. C. et al. (org.) Estado e políticas públicas na Amazônia: gestão do desenvolvimento regional. Belém: Cejup, 2001. p. 216-283.

INSTITUTO BRASILEIRO DE GEOGRAFIA E ESTATÍSTICA - IBGE - REGIC. Regiões de influência das cidades: 2018 / IBGE, Coordenação de Geografia. - Rio de Janeiro: IBGE, 2020.

INSTITUTO DE PESQUISA ECONÔMICA APLICADA. Atlas da Violência 2019. Rio de Janeiro: IPEA, 2019.

JOHNSON, C. MITI and the Japanese Miracle. The Growth of Industrial Policy, 19251975. Stanford: Stanford University Press, 1982.

JOHNSON, C. The Developmental State: The Odyssey of a Concept. In M. WooCumings, ed. The Developmental State. Ithaca/London: Cornell University Press, 1999.

GOMES JÚNIOR, Evaldo. A centralidade do município de Araguaína-TO na Amazônia oriental. In: Anais do XIII Seminário Internacional RII/VI Taller de Editores RIER. Salvador, pp. 1-15, 01 a 04 de setembro de 2014 p. 
LIMA, Juscelino Gomes. Cidades médias brasileiras: a partir de um novo olhar denominal e conceitual: cidades de comando regional. In: ENANPUR -

Desenvolvimento, crise e resistência: quais os caminhos do planejamento urbano e regional?, 17., 2017, São Paulo. Anais [... ]. São Paulo, 2017. p. 2 a 19.

MATA, Daniel da; MOTTA, Diana. Crescimento das cidades médias. IPEA - Boletim Regional e Urbano, IPEA/ Diretoria de Estudos Regionais e Urbanos, n. 1, dez. 2008. Disponível em:

https://www.ipea.gov.br/portal/images/stories/PDFs/boletim_regional/081207_bolet imregional1.pdf. Acesso em: 28 abr. 2020.

MONTE-MÓR, Roberto Luís de Melo. O que é o urbano, no mundo contemporâneo. Belo Horizonte: UFMG/Cedeplar, 2006.

NOGUEIRA, Cláudia Romaneli. Imperatriz: de Vila à cidade comercial e ponto de apoio no desenvolvimento amazônico. Espaço Aberto, PPGG - UFRJ, v. 3, n. 1, p. 129154, 2013.

PERISSINOTTO, Renato. O conceito de Estado Desenvolvimentista e sua utilidade para os casos brasileiro e argentino. Revista de Sociologia Política, v. 22, n. 52, p. 5975, dez. 2014.

PINHEIRO, Karisa. Bases teóricas gerais sobre urbanização no Brasil. RDE - Revista de Desenvolvimento Econômico, Salvador, ano IX, n. 15, p. 61-68, Jan. 2007.

PINHEIRO, Maurício Mota Saboya. As liberdades humanas como bases de desenvolvimento: uma análise conceitual da abordagem das capacidades humanas de Amartya Sen. Rio de Janeiro: IPEA, 2012. (Texto para discussão, 1794).

RAMOS, Edivaldo Fernandes. As cidades médias em perspectiva: uma análise dos papéis e tendências de um grupo de cidades médias brasileiras. 2011. Dissertação (Mestrado em Geografia) - Departamento de Geografia, Universidade Federal de Minas Gerais, 2011.

ROTTA, Edemar; REIS, Carlos Nelson dos. As Práticas do Desenvolvimentismo Brasileiro: Plano de Metas e Programa de Aceleração do Crescimento. Textos \& Contextos, Porto Alegre, v. 17, n. 1, p. 151-166, jan./jul. 2018.

SANTOS, Roberto Souza. A construção da rodovia BR - 153 na fronteira e urbanização da cidade de Araguaína, Tocantins. Novos Cadernos NAEA, v. 20 n. 3, p. 97-114, set./dez. 2017.

SOCIEDADE NACIONAL DE AGRICULTURA - SNA. Agronegócio representou 43\% das exportações brasileiras em 2019. Reportagem de 15/01/2020. Disponível: https://www.sna.agr.br/agronegocio-representou-43-do-total-exportado-pelo-brasilem-2019/. Acesso em 30/08/2020. 
SEN, Amartya. Identidade e violência: a ilusão do destino. São Paulo: Iluminuras, 2015.

SEN, Amartya. Desenvolvimento como liberdade. São Paulo: Companhia das Letras, 2010.

SODRÉ, Reges; RAMIRES, Júlio Cesar de Lima. Contribuições ao estudo de cidades médias: Araguaína, Gurupi e Palmas, no Tocantins. Novos Cadernos NAEA, v. 20, n. 1, p. 169-188, jan./abr. 2017.

SOUSA, I. S. A ponte Rio Negro e a Região Metropolitana de Manaus: adequações no espaço urbano-regional à reprodução do capital. 2013. Tese (Doutorado em Geografia Humana) - Programa de Pós-Graduação em Geografia Humana, Universidade de São Paulo, 2013.

SPOSITO, M. E. B. O desafio metodológico da abordagem interescalar no estudo de cidades médias no mundo contemporâneo. CIDADES, v. 3, n. 5, p. 143-157, 2006.

TELES, Marcela Pereira. Políticas redistributivas em Araguaína-TO: consequências do Programa Bolsa Família a partir dos dispositivos lei-família-escola. (Mestrado em Demandas Populares e Dinâmicas Regionais) - Programa de Pós-graduação em Demandas Populares e Dinâmicas Regionais, Universidade Federal do Tocantins, 2020.

TRINDADE JÚNIOR, Saint-Clair Cordeiro. Uma floresta urbanizada? Legado e desdobramentos de uma teoria sobre o significado da cidade e do urbano na Amazônia. Espaço Aberto, PPGG - UFRJ, v. 3, n. 2, p. 89-108, 2013.

Miguel Pacífico Filho. Professor do Curso de Mestrado em Demandas Populares e Dinâmicas Regionais da Universidade Federal do Tocantins e do Curso de Geografia. Doutor e Mestre em História do Brasil pela UNESP. Graduado em História pela UFOP.E-mail: miguilim@uft.edu.br

Thelma Pontes Borges. Professora do curso de Mestrado em Demandas Populares e Dinâmicas Regionais da Universidade Federal do Tocantins. Doutora em Psicologia Escolar e do Desenvolvimento Humano pela USP. Mestre em Educação pela UNESP. Graduada em Psicologia pela UNESP. E-mail: thelmapontes@uft.edu.br

Marcela Pereira Lima Teles. Mestre em Demandas Populares e Dinâmicas Regionais e Geógrafa pela Universidade Federal do Tocantins. Professora da Rede Pública Estadual do Tocantins. E-mail: marcelaplteles@gmail.com

Airton Cardoso Cançado. Docente do Programa de Pós-graduação em Desenvolvimento Regional e do Curso de Administração da Universidade Federal do Tocantins. Doutor em Administração pela Universidade Federal de Lavras. Mestre em Administração pela Universidade Federal da Bahia e Graduado em 
Administração pela Universidade Federal de Viçosa. E-mail: airtoncardoso@yahoo.com.br

Como citar: PACÍFICO FILHO, Miguel et al. Cidades Médias na Amazônia Legal: Araguaína/TO, Imperatriz/MA e Marabá/PA - indutoras de desenvolvimento e desigualdades. Redes (St. Cruz Sul, Online), Santa Cruz do Sul, v. 25, p. 1477-1503, nov. 2020. ISSN 1982-6745. doi:https://doi.org/10.17058/redes.v25i0.15139.

\section{CONTRIBUIÇÃO DE CADA AUTOR}

a. Fundamentação teórico-conceitual e problematização: Miguel Pacífico Filho, Thelma Pontes Borges e Marcela Pereira Lima Teles

b. Pesquisa de dados e análise estatística: Miguel Pacífico Filho, Thelma Pontes Borges e Airton Cardoso Cançado

c. Elaboração de figuras e tabelas: Miguel Pacífico Filho, Thelma Pontes Borges e Marcela Pereira Lima Teles

d. Fotos: não se aplica

e. Elaboração e redação do texto: Miguel Pacífico Filho e Thelma Pontes Borges

f. Seleção das referências bibliográficas: Miguel Pacífico Filho, Thelma Pontes Borges, Marcela Pereira Lima Teles e Airton Cardoso Cançado

Fontes de financiamento: não se aplica. 